\title{
Adipsic Diabetes Insipidus
}

National Cancer Institute

\section{Source}

National Cancer Institute. Adipsic Diabetes Insipidus. NCI Thesaurus. Code C129637.

Diabetes insipidus complicated by a deficient or absent thirst response to

hyperosmolality, usually as a result of hypothalamic damage or dysfunction. 